\title{
PERSPECTIVAS
}

Artigo convidado

DOI: http://dx.doi.org/10.1590/So034-759020170409

\section{INTERNACIONALIZAÇÃO DOS PERIÓDICOS BRASILEIROS}

Há uma vasta literatura que trata do processo de internacionalização de empresas, com modelos consolidados e que revelam os desafios enfrentados nos diferentes níveis de internacionalização dos negócios. No entanto, tratando-se de publicação acadêmica, poderíamos assumir ser um negócio, que se beneficiaria com esse conhecimento? A internacionalização dos periódicos acadêmicos na área de Administração do Brasil é recente. Se considerarmos que um dos requisitos principais para a internacionalização seja o uso de língua franca, no caso o inglês, a Brazilian Administration Review $(B A R)$ é pioneira, por publicar, desde o seu primeiro número, em 2004, artigos somente em inglês, com foco claro em ser um periódico internacional. No editorial do primeiro número, Guimarães e Machado-da-Silva (2004) indicaram: “o principal motivo para trazer um jornal de língua inglesa editado por uma associação acadêmica brasileira é que há uma necessidade cada vez maior de levar nosso trabalho científico a um público mais amplo, o que inevitavelmente significa levá-lo a países onde o português não é a língua dominante”. Com base nisso, assumimos que o uso da língua inglesa é um dos requisitos da internacionalização, considerando que a academia internacional se comunica nessa língua. Temos, nesse aspecto, um desafio ainda grande, pois não somos educados nessa língua, e a cobrança para o correto domínio do inglês no meio acadêmico restringe-se, na maioria das vezes, à leitura e compreensão de texto, não englobando a redação acadêmica. No entanto, esse não é o principal desafio para a internacionalização, embora seja uma barreira inicial para tal. Destaca-se que, mais do que para o domínio da língua inglesa, deve-se atentar para a qualidade dos artigos e a autoria de artigos em parcerias com autores estrangeiros, bem como para a necessidade de um corpo editorial diverso e ativo, como questões ainda mais desafiadoras no processo de internacionalização dos periódicos.

Para competir no mercado editorial internacional, se estabelece a perspectiva de que o caminho para a internacionalização passa pela profissionalização editorial, em que um publisher (casa editorial) será responsável pelas partes operacional e gerencial, e a parte acadêmicocientífica será responsabilidade de um corpo editorial diversificado e de excelente reputação acadêmico-científica. Por exemplo, podemos mencionar a Revista de Administração da Universidade de São Paulo (RAUSP), também agora denominada Management Journal, que, no esforço de internacionalização, conta atualmente com os serviços da Elsevier. Usualmente, no exterior, os periódicos pertencem a um publisher, e não a um programa de pós-graduação, como é o caso do Brasil. Aqui, praticamente todos os programas de pós-graduação possuem um periódico, o

SALOMÃO ALENCAR DE FARIAS saf@ufpe.br

Professor da Universidade Federal de Pernambuco,

Programa de Pós-Graduação em Administração - Recife - PE, Brasil que leva a um número extenso, mas não necessariamente de qualidade, entre os quais poucos conseguirão ter sucesso no processo de internacionalização. “Essa grande quantidade de revistas talvez cause efeitos de dispersão e de nivelamento por baixo da qualidade dos artigos científicos publicados em periódicos brasileiros", disse Isabelle Reiss, gerente de contas da divisão de pesquisa científica da Thomson Reuters para a América do Sul. Segundo ela, uma menor quantidade de 
periódicos brasileiros tornaria a seleção de artigos mais rigorosa e, consequentemente, aumentaria a qualidade e a visibilidade dos trabalhos publicados (Alisson, 2013). No entanto, esse modelo, dominante em países como os Estados Unidos, pode não ser o único caminho para a internacionalização. Os publishers geralmente cobram pelo acesso aos periódicos e/ou cobram pelo serviço operacional, quando não são os proprietários dos periódicos. O que vivenciamos em nossa área é que o conhecimento gerado e divulgado por publicações consolidadas e dominantes (chamaremos aqui de mega journals) em áreas específicas acaba restrito às instituições e/ou indivíduos que podem pagar pelo acesso. Existe, nessa situação, uma questão de controle relacionada ao conhecimento gerado. No Brasil, os periódicos de maior impacto em Administração adotam o acesso aberto e têm que buscar recursos em editais ou nas próprias instituições as quais os periódicos estão vinculados para sua continuidade. Um orçamento “adequado” também é uma condição necessária para a internacionalização, e, considerando a escassez de financiamento de órgãos como o CNPq e CAPES para tal fim, poucos periódicos conseguirão manter uma periodicidade e qualidade adequadas para competir com diferentes pares no mundo.

Para Fradkin (2017), a internacionalização bem-sucedida de periódicos, além do conteúdo em inglês de boa qualidade, deve contemplar outros dois elementos: que a instituição do primeiro autor e os membros do conselho editorial pertençam a um país nativo de língua inglesa, e que os artigos descrevam estudos empíricos Segundo esse autor, para que haja uma internacionalização de sucesso, os periódicos devem assumir dois caminhos: aumentar o número de artigos publicados em língua inglesa e a colaboração com autores nativos de língua inglesa. A chave para a internacionalização das revistas brasileiras envolve o aporte brasileiro à expertise de língua-franca (inglês), e a especialização, em termos de editores experientes, revisores, editores e autores. São necessários profissionais que sejam nativos de países onde o inglês é a língua oficial para elevar os padrões das revistas no Brasil (Fradkin, 2017).

Um caminho indicado pelo SciELO desde 2016 consiste em que se fortaleça a participação e colaboração de autores e especialistas nos comitês editoriais com afiliação estrangeira. Ou seja, para que a ciência alcance a internacionalização, se colocam os especialistas nativos de países de língua inglesa como centrais no processo de editoria e autoria. Para o SciELO, há metas específicas para a área de ciências sociais aplicadas para que periódicos sejam admitidos e continuem nessa base de dados, tais como porcentagens mínimas esperadas de editores associados ativos com afiliação institucional no exterior: o mínimo é de $15 \%$, e o recomendado, $25 \%$, para as ciências sociais. Os novos critérios incluem, ainda, porcentagens anuais mínimas esperadas e recomendadas de autores com afiliação institucional no exterior (SciELO, 2014). Aí reside mais um desafio de atrair autores estrangeiros para submeterem artigos a periódicos classificados como A no Qualis CAPES, mas com fatores de impacto ainda pouco competitivos para atrair os melhores artigos de pesquisadores estrangeiros e competir com igualdade com os mega journals de nossa área.

Reforçando o apresentado no final do parágrafo anterior, informação disponibilizada pela Agência FAPESP (Alisson, 2013) indicou que as revistas científicas de países emergentes, como China, Coreia do Sul, Rússia e Brasil, têm intensificado seu processo de internacionalização - que pode ser medido pelo número de artigos publicados em inglês, citação por outros países e pela publicação de artigos de autoria de pesquisadores estrangeiros, entre outros indicadores. Os periódicos brasileiros, contudo, estão atrás das coleções desses outros países na corrida pela internacionalização, uma vez que ainda publicam menos artigos em inglês e em colaboração com o exterior.

Ao discutir internacionalização de periódicos, deve-se considerar o fator de impacto, pois a competição é global, e os pesquisadores renomados e os melhores artigos terão como destino aqueles com fator de impacto mais alto. Há diferentes rankings comparativos disponíveis para que um autor decida para qual periódico enviar os resultados de suas pesquisas. Por exemplo, o ranking SCImago Journal \& Country Rank, um portal que inclui indicadores científicos de periódicos e países, desenvolvido a partir das informações contidas na base de dados SCOPUS, que apresenta a RAE e a BAR no quartil Q3, com fator de impacto $\mathrm{H}$ index 6, e o indicador Scimago SJR de 0.207 e 0.188, respectivamente. O SCImago Journal Rank (indicador SJR) é uma medida da influência científica de revistas acadêmicas que explica o número de citações recebidas por uma revista e a importância ou prestígio das revistas de onde provêm essas citações. Em um total de 14 periódicos na América Latina na área de negócios, a $R A E$ está na quarta posição e a $B A R$, na sexta, nesse portal. Já no Google Scholar, o fator de impacto da RAE h-5 é 20 e o da BAR é 13. Comparativamente, o Journal of Management tem um h-5 igual a 79. Ou seja, em termos de América Latina, o Brasil tem uma posição que pode ser considerada competitiva. Mas, quando ampliamos a comparação, os periódicos nacionais ainda ficam distantes dos mega journals internacionais.

Segundo Carvalho e Sasseron (2014), no domínio das ciências sociais, vários autores já indicaram a falta de equilíbrio de poder na produção de conhecimento no nível global, com uma grande concentração nos países capitalistas, 
metrópoles ou nações "do Norte” - com mais senso político do que geográfico. As autoras continuam indicando que a internacionalização de periódicos na área das ciências sociais é um processo contraditório e complexo, que só pode ser entendido no contexto da divisão internacional do trabalho intelectual. A área de discussão abordada pelas autoras é a da educação, mas possivelmente o posicionamento delas, de alguma forma, pode ser aplicado à Administração.

O processo de internacionalização, na opinião de Diniz (2011), não é uma tarefa fácil. Além de falarmos português, e não podermos simplesmente abrir mão desse nosso privilégio, temos que buscar presença em indexadores internacionais relevantes, atrair autores estrangeiros para fazer parte de nossos comitês científicos, fazer chamadas de trabalho internacionais e umas tantas outras tarefas nada simples de executar, embora óbvias de planejar. Parece contraditório o conflito de produzirmos e publicarmos em português, mas, para nos internacionalizarmos, temos que abrir mão disso e nos centrar na produção em inglês, seguindo recomendações de formatação APA e não ABNT, essa última ainda adotada na produção de dissertações e teses em nossos programas de pós-graduação.

Para Silva, Carvalho, Amaro e Assis (2016), deve-se refletir também sobre a necessidade da busca do equilíbrio entre o binômio quantidade x qualidade. Grande parte das revistas brasileiras, e nesse caso tanto revistas científicas de acesso aberto como de outros modelos de negócios, ainda não alcançou posições de destaque nas chamadas "grandes bases de dados indexadoras internacionais", tais como a JCR e SJR. Aumentar a presença brasileira nesses indexadores internacionais é muito importante, já que, ao estar neles presente, o efeito esperado será o crescimento da visibilidade da ciência nacional, aumentando o seu número de citações e, assim, possibilitando a criação de novas redes de colaboração e produção de conhecimento científico. Aqui, mais uma vez, emerge outro desafio: atrair autores estrangeiros com reputação e conhecimento em suas áreas de especialidade para submeterem artigos aos nossos periódicos. Gerar citações e incrementar indexadores não é um processo fácil nem rápido, se feito com princípios éticos.

Embora a publicação de artigos em inglês seja algo necessário, Fradkin (2017) indica que apenas o percentual de textos em língua inglesa presentes nos periódicos nacionais não mostrou correlação com o grau de internacionalização destes. Os outros critérios, como a maior prevalência de membros do conselho editorial não brasileiros originários de países de língua inglesa, maior percentual de autores com afiliação institucional de países de língua inglesa e maior proporção de artigos de natureza empírica, mostraram correlação com o grau de internacionalização dos periódicos. Ou seja, em um país onde não somos alfabetizados em inglês, onde na pós-graduação exige-se, de modo geral, apenas o domínio da leitura em inglês, e o domínio da escrita acadêmica nessa língua ainda é limitado, o esforço mais lógico, e, de modo geral, a condição quase sine qua non, não demonstrou ser o mais significativo no processo de internacionalização. Compreende-se que se deve ter artigos escritos em inglês, mas com parceiros internacionais, para aumentar as chances de internacionalização de um periódico.

Packer (2014) menciona que os melhores periódicos internacionais contam com um grande orçamento, equipe profissional adequada e em tempo integral, são digitais e apresentam sistema de gestão digital, e fazem uso de uma casa editora (publisher) que publica várias revistas. Especificamente no campo das ciências humanas e sociais, os periódicos tendem a apresentar os seguintes problemas: as limitações das equipes editoriais afetam a gestão da produção dos periódicos; o contexto cultural, social, acadêmico e financeiro privilegia a publicação em português; a internacionalização da gestão editorial não é percebida como um avanço natural, necessário e possível; e as limitações que afetam a qualidade da produção científica/ acadêmica nas áreas humanas e sociais surgem como barreiras para a internacionalização dos periódicos. O que se produz na pós-graduação, os problemas da pós-graduação, acabam refletidos nos periódicos vinculados a estes programas de pósgraduação. Pesquisas desenvolvidas no Brasil, por vezes pouco colaborativas e internacionalizadas, não são de interesse no contexto internacional. Percebe-se aí um problema de ordem cultural que deve ser explorado na formação dos pesquisadores, dentro dos programas de pós-graduação, de modo que passemos a treinar doutorandos para a avaliação de artigos, exigir a produção de artigos em inglês e estabelecer que a visibilidade da nossa pesquisa só acontecerá por meio da produção em uma língua que seja de domínio comum.

Certamente os editores de periódicos na área da Administração no Brasil terão um grande desafio no rumo à internacionalização e competindo globalmente pelos melhores artigos e autores com ilibada reputação. Talvez a lei da sobrevivência dos mais fortes vá se aplicar nesse processo, e apenas um número restrito de periódicos brasileiros alcançará no futuro o patamar dos mega journals. Haverá, certamente, os periódicos que não percorrerão o caminho da internacionalização e aqueles que lutarão por espaço no contexto global. Sem adotar uma abordagem ideológica, mas sim pragmática, acredito que o caminho para a internacionalização está obrigatoriamente em publicar em inglês, em cooperação com pesquisadores estrangeiros, ter rigor na avaliação dos artigos, um corpo 
editorial diversificado que inclua estrangeiros comprometidos e participativos nos processos do periódico, profissionalização do periódico com a contratação de um publisher, e até, futuramente, a "venda" dos periódicos aos publishers internacionais, bem como a especialização de algumas revistas em áreas funcionais da Administração, a exemplo do que existe em outros países.

\section{REFERÊNCIAS}

Alisson, E. (2013). Revistas científicas de países emergentes aumentam processo de internacionalização. Agência FAPESP. Recuperado de http://agencia.fapesp.br/revistas_cientificas_de_paises_emergentes_aumentam_processo_de_internacionalizacao_/18142/

Carvalho, M. P. de, \& Sasseron, L. H. (2014). The internationalization of Brazilian education journals: Tensions of an ongoing process. Educação e Pesquisa, 40(4). doi:10.159o/S1517- 970220144004001
Diniz, E. (2011). Editorial. Internacionalização dos periódicos nacionais. RAE-Revista de Administração de Empresas, 51(4). doi:10.1590/ So034-75902011000400001

Fradkin, C. (2017). The internationalization of psychology journals in Brazil: A bibliometric examination based on four indices. Paideia, 27(66). doi:10.1590/1982-43272766201702

Guimarães, T. de A., \& Machado-da-Silva, C. L. (2004). Editorial. BAR-Brazilian Administration Review, 1(1). doi:10.1590/S180776922004000100001

Packer, A. (2014). A internacionalização dos periódicos foi tema central da IV Reunião Anual do SciELO [online]. SciELO em Perspectiva. Retrieved from http://blog.scielo.org/blog/2014/12/16/a-internacionalizacao-dos-periodicos-foi-tema-central-da-iv-reuniao-anual-do-scielo/

SciELO. (2014, Setembro). Critérios, política e procedimentos para a admissão e a permanência de periódicos científicos na Coleção SciELO Brasil. Scientific Electronic Library Online. São Paulo, SP.

Silva, D. M., Carvalho, T. de O., Amaro, B., \& Assis, T. B. (2016). 0 retrato situacional das revistas científicas brasileiras. Cadernos BAD, 2, 116-124. 